\title{
Comparative Study of Intraocular Pressure (IP) in Bangladeshi Individuals by Contact and Non Contact Technique
}

\author{
Sayed Abdul Wadud ${ }^{1}$, Md Sharfuddin Ahmad ${ }^{2}$, Muntasir - Bin - Shahid ${ }^{3}$ \\ ${ }^{1}$ Assost Prof, ${ }^{2}$ Chairnan, ${ }^{3}$ Resident, Department of Department of Community ophthalmology, BSMMU.
}

\begin{abstract}
:
Background: Intraocular pressure (IOP) is one of the most important parameters in the diagnosis and treatment of glaucoma'. Glaucoma has been established as the second leading cause of blindness. The treatment of glaucoma focuses mainly on lowering intraocular pressure (IOP). The target IOP is often set to a level $20 \%$ to $30 \%$ of IOP reduction, and consequent large IOP reduction beyond $30 \%$ or even $40 \%$ in cases of advanced glaucoma ${ }^{2}$. The different methods of tonometery are: Goldman Applanation tonometery, Noncontact (air-puff) tonometery, Perkins tonometery, Tonopen tonometery, Transpalpebral tonometery. Objective: To determine the frequency of accuracy of intraocular pressure (IOP) measured by non-contact (air puff) tonometer compared with Goldmanı applanation tonometer. Methods: This was a non-interventional, cross sectional study con-ducted at a tertiary care centre of Dhaka, Bangladesh. consecutive subjects attending the BSMMU eye OPD were included in the study. IOP was measured by non-contact (air puff) tonometer and a slit lamp mounted GAT in all the subjects. The study samples were selected by convenience sampling who presented for check-up in the Eye Department of community ophthalmology, Bangabandhu Sheikh Mujib Medical University, Dhaka. Bangladesh. Results:A total of 120 eyes in 60 patients were studied. The mean age of the patients was 41.60 year. study population consisted of $24(40 \%)$ men and $36(60 \%)$ women. The mean intraocular pressure was $13.52 \& 13.72 \mathrm{mmHg}$ for GAT, and $16.64 \& 17.44 \mathrm{mmHg}$ for Air puff respectively. The range of measurements by GAT was from 10 to $23 \mathrm{mmHg}$ and by Air puff was 12 to $28 \mathrm{mmHg}$. The difference between IOP measured by two instruments were statistically significant $(p=0.000)$. Conclusion: Airpuff tonometer is quick, a non-contact method to measure intraocular pressure and is useful for screening purposes and postoperative case but the measurements should be confirmed with Goldmann applanation tonometer for accurate labelling of intraocular pressure.
\end{abstract}

Keywords: Glaucoma, Intraocular pressure, Goldmann applanation tonometry, Non-contact air puff tonometer.

[BSMMUJ $2015 ; 8(1): 56-60]$

\section{Introduction:}

Intraocular pressure (IOP) is one of the most important parameters in the diagnosis and treatment of glaucoma'. Glaucoma has been established as the second leading cause of blindness ${ }^{3}$. The treatment of glaucoma focuses mainly on lowering intraocular pressure (IOP). The target IOP is often set to a level $20 \%$ to $30 \%$ of IOP reduction, and consequent large IOP reduction beyond $30 \%$ or even $40 \%$ in cases of advanced glaucoma ${ }^{2}$. The different methods of tonometery are: Goldman Applanation tonometery, Noncon-

Address for Correspondence: : Sayed Abdul Wadud

Assost Prof Department Of community ophthalmology,

Bangabandhu Sheikh Mujib Medical University (BSMMU), Bangladesh. tact (air-puff) tonometery, Perkins tonometery, Tonopen tonometery, Transpalpebral tonometery.

Goldmann Applanation Tonometer is the method of choice in the ophthalmological clinical settings. Based on Imbert-Fick principle, the Goldmann tonometer assesses the intraocular pressure by measuring the force necessary to applanate a fixed area of cornea ${ }^{3}$. Air puff tonometry is based on the principle of Applanation, the central part of cornea is flattened by a jet of air to measure the level of IOP $^{5}$. The main advantages of non-contact tonometers are that they are non-invasive and thus comfortable for the patient with a minimal risk of infection. The performance of non-contact tonometery and the interpretation of results are easier than with Gold- 
mann tonometery.

The reliability and stability of IOP measurements is very important. Normal IOP is important to maintain the shape of the eye and normal visual function. Longterm high IOP can cause irreversible damage to the retinal ganglion' cells and postganglionic nerve fibres. Studies have shown that for every $1 \mathrm{mmHg}$ reduction in IOP, visual field damage can be reduced by $10 \%$.

Pooled data from large epidemiologic studies indicate that the mean IOP is approximately $16 \mathrm{mmHg}$; however, these pooled data have a non-Gaussian distribution with a skew toward higher pressures, especially in individuals over the age of 40 . The value $22 \mathrm{mmHg}$ has been used in the past to both separate normal and abnormal pressures and define which patients required ocular hypotensive therapy. This division was based largely on the erroneous assumptions that glaucomatous damage is caused exclusively by pressures that are higher than normal and that normal pressures do not cause damage.

\section{Methods:}

This was a non-interventional, comparative cross sectional study conducted Bangabandhu Sheikh Mujib Medical University, Dhaka, Bangladesh. Consecutive subjects attending the BSMMU community ophthalmology OPD were included in the study. IOP was measured by non-contact (air puff) tonometer and a slit lamp mounted GAT in all the subjects. The study samples were selected by convenience sampling who presented for check-up in the Eye Department of community ophthalmology, Bangabandhu Sheikh Mujib Medical University, Dhaka. Bangladesh. Inclusion criteria includes ,best corrected visual acuity (BCVA) at least $6 / 6$, refractive error within $\pm 2 \mathrm{D}$ spherical and within $\pm 2 \mathrm{D}$ of astigmatism.15, the subjects with normal fundus on $+90 \mathrm{D}$ examination. Exclusion criteria includes , refractive error $> \pm 2 \mathrm{D}$, any active eye disease like uveitis, corneal disease, infec-tion, discharge, etc, any condition that did not allow taking measurements.Both the procedures were explained to the subjects and an informed consent was taken according to the Declaration of Helsinki, All the measurements were taken from $9 \mathrm{AM}$ to $10 \mathrm{AM}$ to avoid the effect of diurnal fluctuations on IOP. Measurement by Air puff tonometer this was done first in each patient followed by Goldman applanation tonometry. It was done before applanation tonometry because touching the comea by applanation prism might have effect on non-contact (air puff) tonometer readings.16-22 The subjects were made to sit on a chair and IOP was mea-sured by non-contact (air puff) tonometer. The average of three measurements was taken for analysis. Measurement by GAT: the applanation tonometry was done by a slit lamp mounted applanation tonometer on Haag-Streit R-900 device (Haag-Streit, Koeniz, Switzerland). The subjects were seated comfortably on the slit lamp after explaining the procedure. Proparacaine (0.5\%) eye drops were instilled as an anaesthetic agent followed by application of sterilized strip of Flourescein (1\%) in the inferior fornix of the eye.2,3,23-The applanation prism tip was cleaned by alcolhol to avoid transmission of infection. 23 The time difference of at least $15 \mathrm{~min}$ was kept between the two measurements. The readings were taken by properly calibrated GAT. The standard clinical methods, recommendations and guidelines of the manufacturers were followed for appropriate readings.23 Three different readings for the designated eye were and the average was calculated which was used for statistical analysis.
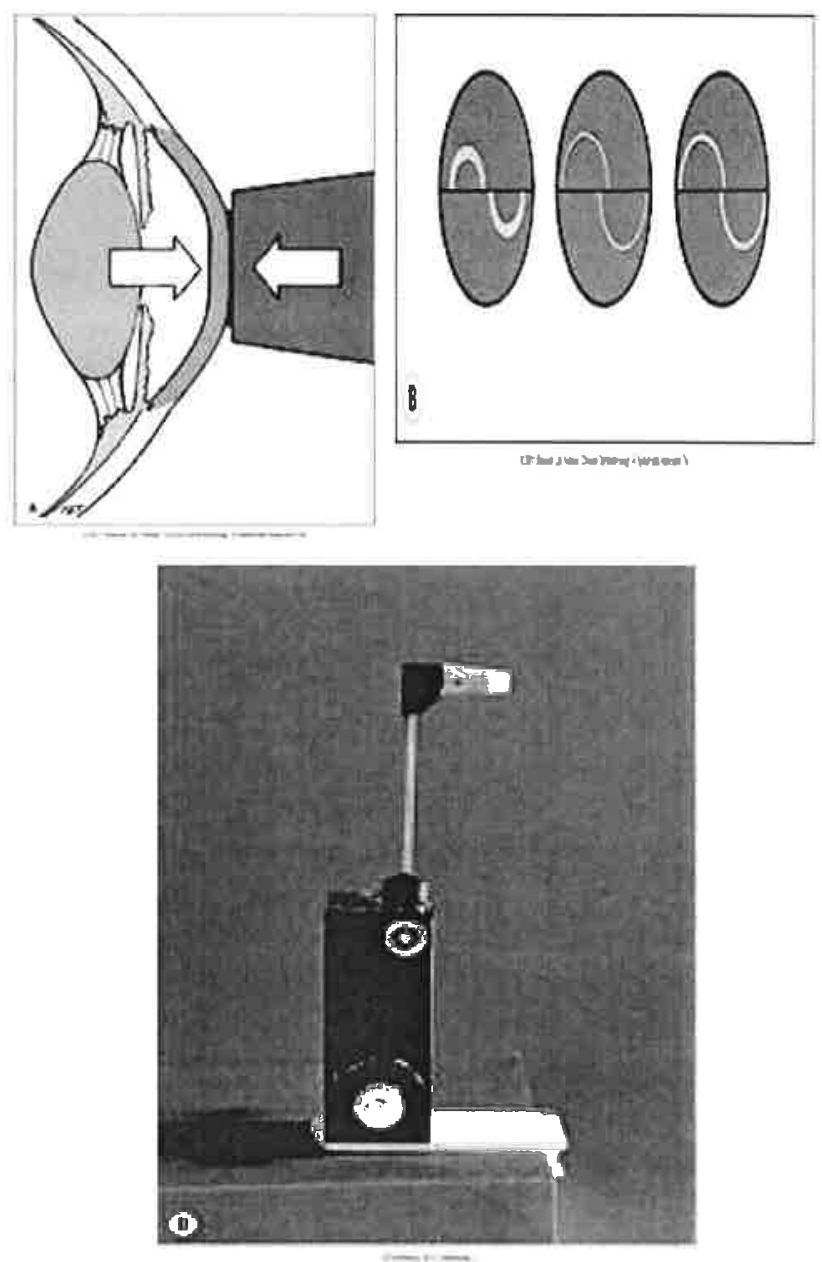

Fig: 1 Goldman Applanation tonometry 


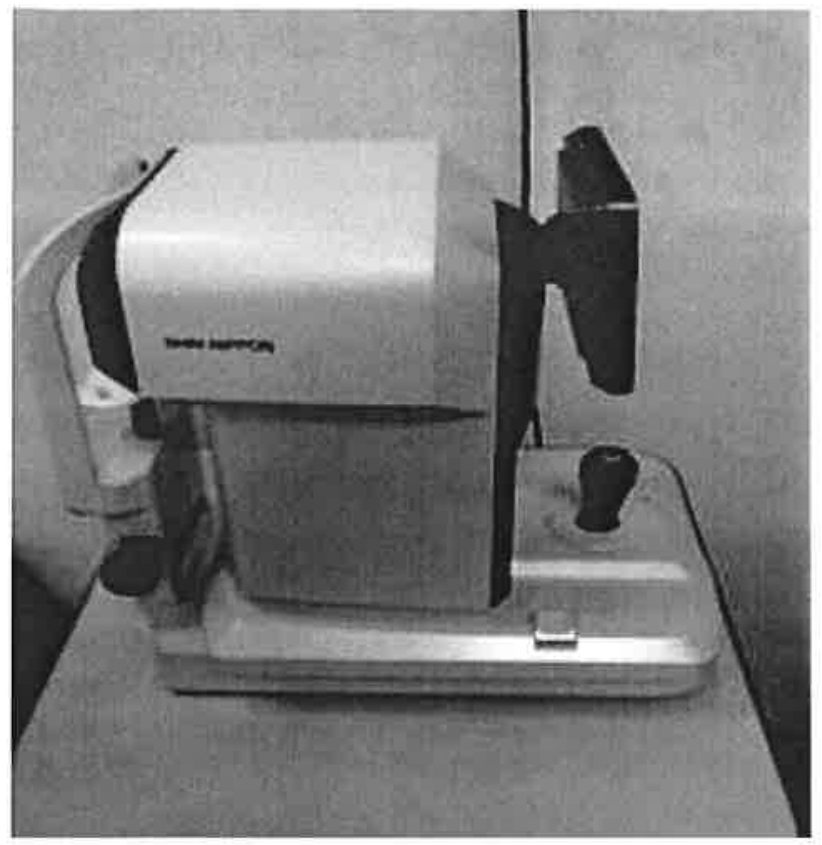

Fig: 2 Non Contact Airpuff Toometer 200(NIPPON)

The data were entered in Microsoft excel spread sheet. Statistical analysis was done with SPSS 16 software (Chicago,IL, USA). The mean IOP measured by each instruments were compared. Student's t-test was performed to compare the mean IOP obtained with two methods. was used to explore correlation between the two methods of IOP measurements. A p-value of $<0.05$ was taken as significant.

\section{Results:}

A total of 120 eyes in 60 patients were studied. The mean age of the patients was 41.60 year. study population consisted of $24(40 \%)$ men and $36(60 \%)$ women. The mean intraocular pressure was $13.52 \& 13.72 \mathrm{mmHg}$ for GAT, and $16.64 \& 17.44 \mathrm{mmHg}$ for Air puff respectively. The range of measurements by GAT was from 10 to $23 \mathrm{mmHg}$ and by Air puff was 12 to $28 \mathrm{mmHg}$. The difference between IOP measured by two instruments were statistically significant $(p=0.000)$.

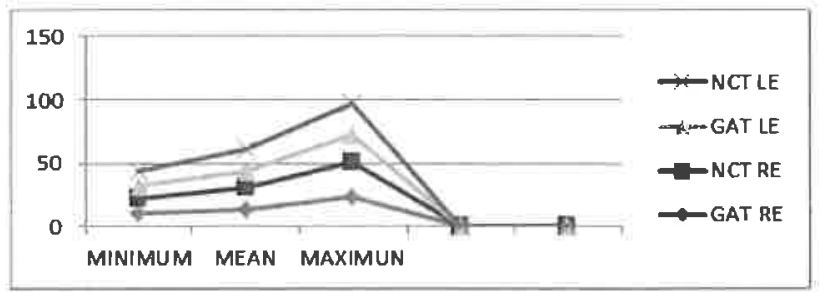

Fig : 3 IOP trend

In our study a total of 120 eyes in 60 patients were studied. The mean age of the patients was 41.60 year. study population consisted of $24(40 \%)$ men and 36 (60 $\%$ ) women (Table-01,02, Figure-03).

Table - J

Results of IOP in GAT and airpuff with mean and number of patient

\begin{tabular}{lccc}
\hline & N & Mean & Std. Deviation \\
\hline patient age & 50 & 41.6000 & 14.44483 \\
GAT in right eye & 50 & 13.5200 & 3.23400 \\
GAT in left eye & 50 & 13.7200 & 3.11048 \\
Air Puff inRight eye & 50 & 16.6400 & 3.73489 \\
Air puff in left eye & 50 & 17.4400 & 3.44140 \\
\hline
\end{tabular}

The mean intraocular pressure was $13.52 \& 13.72$ $\mathrm{mmHg}$ for GAT, and $16.64 \& 17.44 \mathrm{mmHg}$ for Air puff respectively (Table $-04,05$ Figure -04 ). The range of measurements by GAT was from 10 to $23 \mathrm{mmHg}$ and by Air puff was 12 to $28 \mathrm{mmHg}$. The difference between IOP measured by two instruments were statistically significant $(\mathrm{p}=0.000)$ (Table 05$)$.

Table - II

Results of IOP in GAT and airpuff with mean and number of patient with $P$ value and $C I$

Test Value $=0$

$95 \%$ Confidence
Interval of the
Difference
Mean Difference
Lower Upper

GAT in $31.190 \quad 49 \quad .000 \quad 13.72000 \quad 12.8360 \quad 14.6040$

left eye

$\begin{array}{llllll}\text { Air puff } 35.834 & 49 & .000 & 17.44000 & 16.4620 & 18.4180\end{array}$ in left

eye

\section{Discussion :}

Non Contact Air Puff Tonometer are usually commonly used in day-to-day ophthalmic clinic practice. Its accuracy is very good even in edematous or irregular corneas, less dependent on corneal thickness, can be used in upright or supine positions, no need of Fluoresce. It does not require slit lamp and topical anaesthesia. Disadvantages of Pneumatonometer is expensive. GAT has two disadvantages. 
First, the instrument probe must come into direct contact with the cornea, which can increase the risk of infection. Second, use of the GAT requires a topical anaesthetic, and some patients, especially children, are unwilling or unable to tolerate diug instillation. With these factors in mind, several non-contact tonometers have been developed to facilitate measurement of IOP during vision screening. Several comparative studies have demonstrated the reliability and accuracy of IOP measurements obtained with non-contact tonometers and their correlation with measurements obtained with the GAT in subjects with and without glaucoma. Babalola $\mathrm{OE}$ et al, the accuracy of two non-contact tonometers, including the Reichert AT550, Goldmann applanation tonometer, and a Perkins tonometer was tested in a young normal population. The results showed a high level of agreement between the AT550 and Goldmann applanation tonometer6. Masood Alam Shah et al in their study, concluded that intraocular pressure readings obtained by AT550 are comparable clinically with those obtained by the Goldmann applanation tonometer in a population having intraocular pressure within the normal range. In their study the difference between IOP measured by two instruments were statistically significant $(p=0.03)$.In the study by Salim et al a close level of agreement in the normal range of IOPs was observed, with an increased variation as the magnitude of measurements increased. Our data also highlighted that there were $86.4 \%$ of eyeshaving IOP variations within $\pm 3 \mathrm{mmHg}$. Study done by Moseley et al.showed that $71 \%$ of the patients had IOP variation within $\pm 3 \mathrm{~m} \mathrm{Hg}$. Babalola et al. found that $79 \%$ of patients were within \pm 3 $\mathrm{mmHg}$. The mean of the paired difference in IOP was lesser in IOP less than 18 than above that. These differences in IOP were more common at the higher IOP ranges than the IOP in lower teens. This indicated that in most of the patients the Keeler's Pulsair NCT measured IOP correctly if it was within normal range but one has to become cognisant if measured IOP is $18 \mathrm{mmHg}$ or above with Pulsair NCT. They concluded that NCT is a fair tool for screening purposes in community practices as can be easily used by residents and health care personals. The reliability of the instrument decreases if IOP is in the range of higher teens. In this study we also observed IOP variations within \pm 3 $\mathrm{mmHg}$ and differenc were also statistically significant $(p=0.000)$

\section{Conclusions :}

Compared to non-contact air-puff tonometer, the Gold- mann applanation tonometer is a reliable and consistent technique for measurement of intraocular pressure. Airpuff tonometer is quick, a non-contact method to measure intraocular pressure and is useful for screening purposes and postoperative case .

\section{References:}

1. Kass MA, Heuer DK, Higginbothan EJ, The Ocular Hyperten-sion Treatment Study: a randomized trial determines that topical ocular hypotensive medication delays or prevents the onset of primary open angle glaucoma. Arch Ophthalmol.2002;120:701---713.

2. Kniestedt C, Punjabi O, Lin S, Stamper RL. Tonometry through ages. Surv Ophthalmol. 2008;53:568---591.

3. Goldmann H, Schmidt T. Über Applanations tonometrie. Oph-thalmologica. 1957;134:221---242

4. Forbes M, Pico G, Grolman B. A noncontact applanation tonometer. Description and clinical evaluation. Arch Ophthalmol. 1974;91:134---140.

5. Vernon SA. Reproducibility with the Keeler Pulsair 2000 non-contact tonometer. Br J Ophthalmol. 1995;79:554---557.

6. Babalola $\mathrm{OE}$, Kehinde AV, Iloegbunam AC, Akinbinu $\mathrm{T}$, Moghalu C, Onuoha I. A comparison of the Goldmann applanation and non-contact (Keeler Pulsair EasyEye) tonometers and the effect of central corneal thickness in indigenous African eyes. Oph-thalmic Physiol Opt. 2009;29:182---188.

7. Mackie SW, Jay JL, Ackerley R, Walsh G. A Clinical compar-ison of the Keeler Pulsair 2000, American Optical MkII and Goldmann applanation tonometers. Ophthalmic Physiol Opt.1996;16:171---177.

8. Yücel AA, Stürmer J, Gloor B. Comparison of tonometry with the Keeler air puff non-contact tonometer Pulsair and the Goldmann applanation tonometer. Klin Monatsbl Augenheilkd, 1990;197:329---334.

9. Moseley MJ, Evans NM, Fielder AR. Comparison of a new non-contact tonometer with Goldmann applanation. Eye (Lond). 1989;3:332---337.

10. Wang D, Huang W, Li Y, et al. Intra ocular pressure, central comeal thickness and glaucoma in Chinese adults: the Liwan eye study. Am J Ophthalmol. 2011;152:454---462.

11. Shimmyo M, Ross AJ, Moy A, Mostafavi R. Intraocular pressure, Goldmann applanation tension, comeal thickuess, and comeal curvature in Caucasians, Asians, Hispanics, and African Ameri-cans. Am J Ophthalmol. 2003;136:603---613.

12. Nomura $H$, Ando $F$, Niino $N$, Shimokata $H$, Miyake $Y$. The rela-tionship between age and intraocular pressure in a Japanesepopulation: the influence of central comeal thickness. Curr EyeRes. 2002;24:81---85.

13. Gupta V, Sony P, Agarwal HC, Sihota R, Sharma A. Inter-instrument agreement and influence of central corneal thickness on measurements with Goldmann, pneumotonometer and noncontact tonometer in glaucomatous eyes. Indian $\mathbf{J}$ Ophthalmol. 2006;54:261---265.

14. Chauhan BC, Henson DB. Clinical evaluation of the Non-Contact Tonometer Mark II. Am J Optom Physiol Opt. 1988;65:751---756. 
15. Holladay JT, Allison ME, Prager TC. Goldmann applanation tonometry in patients with regular corncal astigmatism. Am J Oplithalmol. 1983;96:90---93.

16. Fisher JH, Watson PG, Spaeth G. A new handheld air impulse tonometer. Eye. 1988;2:238---242.

17. Pearce CD, Kohl P, Yolton RL. Clinical evaluation of the Keeler Pulsair 2000 tonometer. J Am Opt Soc. 1992;63:106-110 .

18. Sponsel WE, Kaufman PL, Strinden TI. Evaluation of the Keeler Pulsair non-contact tonometer. Acta Ophthalmol (Copenh).1989;67;567---572.

19. Atkinson PL, Wishart PK, James JN. Deterioration in the accu-racy of the pulsair non-contact tonometer with use: need for regular calibration. Eye. 1992;6:530---534.

20. Oguchi KC, Almubrad TM. Accuracy and rcliability of the Keeler Pulsair Easyeye non-contact tonometer. Optom Vi s Sci. 2008;85:61---66.

21. Lawson-Kopp W, DeJong A, Yudcovitch L, Williams S, Kohl P, Yolton RL. Clinical evaluation of the Keeler Pulsair 3000 non-contact tonometer. Optometry. 2002;73:81---90.

22. Vernon SA. Non-contact tonometry in the post-operative eye. Br J Ophthalmol. 1989;73:247---249.

23. Gaton DD, Ehrenberg $M$, Lusky $M$, et al. Effect of repeated applanation tonometry on the accuracy of intraoc-ular pressure measurements. Cur Eye Res. 2010;35: 475---479. 